\title{
Enhancing adaptive capacity for restoring fire-dependent ecosystems: the Fire Learning Network's Prescribed Fire Training Exchanges
}

\author{
Andrew G. Spencer ${ }^{1}$, Courtney A. Schultz ${ }^{1}$ and Chad M. Hoffman ${ }^{1}$
}

\begin{abstract}
Prescribed fire is a critical tool for promoting restoration and increasing resilience in fire-adapted ecosystems, but there are barriers to its use, including a shortage of personnel with adequate ecological knowledge and operational expertise to implement prescribed fire across multijurisdictional landscapes. In the United States, recognized needs for both professional development and increased use of fire are not being met, often because of institutional limitations. The Fire Learning Network has been characterized as a multiscalar, collaborative network that works to enhance the adaptive capacity of fire management institutions, and this network developed the Prescribed Fire Training Exchanges (TREXs) to address persistent challenges in increasing the capacity for prescribed fire implementation. Our research was designed to investigate where fire professionals face professional barriers, how the TREX addresses these, and in what ways the TREX may be contributing to the adaptive capacity of fire management institutions. We evaluated the training model using surveys, interviews, focus groups, and participant observation. We found that, although the training events cannot overcome all institutional barriers, they incorporate the key components of professional development in fire; foster collaboration, learning, and network building; and provide flexible opportunities with an emphasis on local context to train a variety of professionals with disparate needs. The strategy also offers an avenue for overcoming barriers faced by contingent and nonfederal fire professionals in attaining training and operational experience, thereby increasing the variety of actors and resources involved in fire management. Although it is an incremental step, the TREX is contributing to the adaptive capacity of institutions in social-ecological systems in which fire is a critical ecological process.
\end{abstract}

Key Words: adaptive capacity; ecological restoration; Fire Learning Network; fire management; prescribed fire; resilience; workforce capacity

\section{INTRODUCTION}

Prescribed fire is widely accepted by natural resource professionals as an important management tool in fire-adapted ecosystems (Brown et al. 2004, Reinhardt et al. 2008). However, it has been difficult to increase the use of prescribed fire and build workforce capacity in this area (WFLC and NASF 2009, QuinnDavidson and Varner 2012). Given the current primacy of landscape-scale restoration as a management goal in the United States, there is an unmet need for an adequate number of fire professionals with a well-developed understanding of ecological objectives who can work across multiple jurisdictions (Kobziar et al. 2009).

The Fire Learning Network (FLN) was created in 2002 by the Nature Conservancy (TNC) in partnership with the U.S. Forest Service and the land management agencies of the U.S. Department of the Interior. One of the components of the FLN's activities is the Prescribed Fire Training Exchange (TREX) strategy, which was designed to increase local and crossjurisdictional capacity, create collaborative learning opportunities, and promote the use of prescribed fire (TNC, unpublished manuscript). Our study was designed to understand where fire professionals participating in TREX events perceive barriers in their careers, how the TREX model addresses these barriers, and whether it is contributing to increased workforce capacity. These questions have applied value and also provide an opportunity to understand whether and how the TREX component of the FLN contributes to the adaptive capacity of U.S. fire management institutions by acting as a bridging organization that supports collaborative learning, networking opportunities, and innovative solutions for overcoming persistent institutional limitations.
Prescribed fire and the workforce capacity problem

Fire-adapted ecosystems are in need of ecological restoration, and prescribed fire, i.e., when people start or manage fires for specific management objectives, is an essential management tool for restoring these ecosystems and reducing the hazardous fuel loadings that can lead to uncharacteristic, high-severity wildfires (Brown et al. 2004, Kauffman 2004, Reinhardt et al. 2008, Ryan et al. 2013). In the United States, the severity of fires, their extent, and the negative effects on ecosystem services and human infrastructure are all increasing (Brown et al. 2004, Westerling et al. 2011, Gorte 2013). This is in part the result of fire suppression policies of the 20th century, which had significant negative consequences for forest and rangeland health (Pyne 1982, 2010, Busenberg 2004, Dombeck et al. 2004, Stephens and Ruth 2005). The resulting buildup of fuels, when combined with drought, climate change, and the growth of communities to protect in the wildland-urban interface (WUI), has led to the degradation of ecosystems that depend on low- to mixed-severity fires, negative effects on nearby communities, and ballooning fire suppression expenses when uncharacteristically severe wildfires occur (Dellasala et al. 2004, Gorte 2013). The variation in scales at which fire occurs and the multiple jurisdictions that may be involved add to the challenges of fire management (Cummings et al. 2006). Public natural resource management is highly centralized in the United States under the Forest Service and land management agencies of the Department of the Interior, but these public lands are intermixed with a vast array of private and state lands (Rasband et al. 2009). For instance, the WUI, where developed areas lie within or adjacent to public or private wildlands, has more than doubled since 1970 , with nearly $65 \%$ of the WUI on private land in the western United States (Theobald and Romme 2007).

${ }^{1}$ Department of Forest and Rangeland Stewardship, Colorado State University, Fort Collins 
Although mechanical fuel removal, such as tree thinning, is sometimes useful and necessary for restoring ecosystems, fire promotes ecological complexity, e.g., by enhancing biodiversity in the understory, age-class diversity of tree species, and spatial heterogeneity; provides a cost-effective way to maintain the benefits of mechanical treatments; and can be implemented at large scales and on difficult terrain that prohibits mechanical operations (Allen et al. 2002, Pollet and Omi 2002). Although prescribed fire is an important tool for restoring these ecosystems, there are significant hurdles to conducting prescribed fire and increasing the number of acres burned annually. A key barrier is the lack of adequate personnel, in terms of both numbers and skill, who can work across jurisdictions and have sufficient knowledge of ecological conditions; overcoming this requires increased opportunities for professional development and capacity building (Kobziar et al. 2009). The Wildland Fire Leadership Council (WFLC) and the National Association of State Foresters (NASF) found that to maintain current workforce capabilities, without significant new recruitment and training, retirees would have to remain in or temporarily rejoin the workforce (WFLC and NASF 2009). In other cases, researchers have found that the lack of adequate personnel is a greater hindrance to prescribed fire than funding, liability, public opinion, residential proximity, planning, or environmental laws; this lack of personnel can result from the deficiency of quality training assignments (Quinn-Davidson and Varner 2012). New approaches are needed to train the next generation of federal fire professionals and to increase the capacity of nonfederal professionals, landowners, and managers. For adequate preparation of fire professionals, Kobziar et al. (2009) recommend the "fire professional development triangle" model, which incorporates the following: education in fire science, forestry, and ecology; training, in the form of certifications from the National Wildfire Coordinating Group (NWCG); and direct experience with fire operations (see Fig. 1). However, the optimal combination of these three features is often difficult to attain and varies through time as an individual moves into roles that require increasingly complex skill sets.

Fig. 1. The fire professional development triangle as proposed by the Education Committee of the Association for Fire Ecology. Training, experience, and education are all essential components for effective career development in fire (Kobziar et al. 2009).

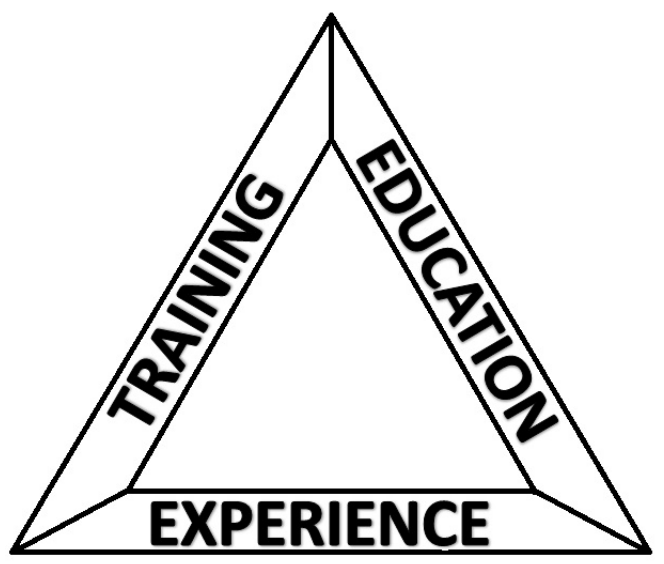

Factors affecting adaptive capacity

In light of the uncertainties and changes expected as a result of climate change, scholars emphasize the importance of maintaining social-ecological systems that are resilient, meaning they have the ability to "absorb disturbance and reorganize while undergoing change so as to still retain essentially the same function, structure, identity, and feedbacks" (Walker et al. 2004). Resilience of a social-ecological system, i.e., a system in which there is a tight link between human and ecological systems and between ecological conditions and ecosystem services, is not always a normative goal or a desirable state. Degraded and polluted landscapes can exhibit a high degree of resilience; however, where society is invested in the preservation of ecosystems and their ecosystem services, resilience is a goal for buffering systems against change (Gunderson and Holling 2002). Restoration is a primary focus of U.S. natural resource agencies to promote resilience of social-ecological systems in fire-adapted landscapes; the goals are to maintain ecosystem conditions and services, reduce threats to health and human infrastructure, and reduce the unsustainable expenses associated with suppressing large or hazardous fires (USDA and USDI 2000, Brown et al. 2004, Schultz et al. 2012).

A key aspect of resilience thinking is the focus on adaptability, or "the capacity of actors in the system to influence resilience" (Walker et al. 2004). Armitage (2005:703) explains that adaptability, also referred to as adaptive capacity, is "a critical aspect of resource management that reflects learning and an ability to experiment and foster innovative solutions in complex social and ecological circumstances." Adaptive capacity may be a characteristic of groups, individuals, organizations, institutions, or a resource governance system (Walker et al. 2004, Pahl-Wostl 2009), and some scholars suggest that adaptive capacity is a characteristic of an entire social-ecological system, dependent on both ecological and social conditions (Le Goff et al. 2005, Armitage and Plummer 2010). "Governance" refers to the range of political, economic, social, and administrative processes that are in place to influence and respond to conditions in a system, and "management" refers to specific actions taken to implement activities and track their effects (Pahl-Wostl 2009). "Institutions" can be understood as the "systems of rules, decision-making procedures, and programs that give rise to social practices, assign roles to the participants in these practices, and guide interactions among the occupants of the relevant roles" (Gupta et al. 2010:460, citing the Institutions Project of the International Human Dimensions Programme). Understanding the relevant institutions is critical to characterizing the governance of a system (PahlWostl 2009). Within the institutional context, a variety of actors and organizations operate. We focus on the adaptive capacity of the institutions involved in fire management and governance; hereinafter, we refer to these as fire management institutions.

Numerous scholars have explored the factors that contribute to adaptive capacity. For instance, resilience thinkers recognize the need for linkages across spatial and temporal scales to enhance learning and adaptive capacity to address ecological challenges (Berkes et al. 2003, Folke et al. 2005). Connections across scales, e.g., large multijurisdictional landscapes versus small singleowner landscapes, and levels, e.g., local, regional, or national organizations or levels of organizations, allow for transference of knowledge accrued over time and also leveraging of comparative 
strengths, i.e., bringing together the knowledge of local organizations with the tools, training, and techniques commonly situated within regional or national organizations (Cash and Moser 2000). Integrating various sources of knowledge also contributes to adaptive capacity by improving society's chances of recognizing when thresholds might be reached and sharing governance strategies that can be adapted to specific contexts (Folke et al. 2005, Lebel et al. 2006).

Also important is the construction of networks that are capable of learning (Folke et al. 2005). Reed et al. (2010) suggest that social learning can be understood as learning that occurs through social interactions between actors in a network and becomes embedded in a broader community of practice. Pahl-Wostl (2009) notes that social learning will be stymied if formal institutions lack the adaptive capacity to support implementation of the lessons learned by actors in a governance system and that more empirical work is needed to understand how and what types of learning contribute to adaptive capacity. Scholars suggest that both the process, e.g., collaborative deliberation and other social interactions, and outcomes, e.g., a change in the collective understanding of a problem and options for addressing it, of social learning are important in contributing to adaptive capacity (Pahl-Wostl 2009, Reed et al. 2010).

Gupta et al. (2010) propose a detailed framework for understanding and measuring factors that contribute to institutional adaptive capacity. The framework includes many of the aforementioned components and also emphasizes the need for adequate resources, fair governance, room for autonomous change and decision making during crises, and variety in actors, problem frames, definitions, and solutions. These characteristics, in addition to social learning and connections across scales and levels, offer guideposts we can use to understand whether and how the TREX may be contributing to the adaptive capacity of fire management institutions.

\section{The rigidity of U.S. fire management institutions, the role of bridging organizations, and the Fire Learning Network}

The ability to build adaptive capacity depends in part on the historical cultural and institutional characteristics of a governance system (Armitage 2005). In the United States, increasing adaptive capacity is a challenge because institutional hierarchies are relatively rigid, limiting the ability to implement ecosystem management across jurisdictions and find innovative solutions to natural resource issues (Garmestani and Benson 2013). For instance, in previous research, Butler and Goldstein (2010) noted that despite widespread recognition of the limitations of fire suppression and the need to focus increasingly on ecological restoration, federal agencies are caught in a cycle, as a result of professional culture, budgetary incentives, and institutional design, that perpetuates an emphasis on fire suppression and constrains both innovation and ecological restoration. A cycle such as this, which preserves the status quo despite a widely recognized need for change, is called a "rigidity trap," whereby organizations and institutions are limited in their ability to incorporate learning and innovation to adapt to new conditions (Gunderson and Holling 2002).

In response to the fire seasons of the early 2000s and to address perceived institutional limitations in the area of U.S. fire management, TNC, in partnership with the Forest Service and land management agencies of the Department of the Interior, created the FLN. At the time, national fire suppression policy garnered public scrutiny as suppression costs swelled, costing more than $\$ 1.3$ billion during the 2000 fire season alone (Kostishack and Rana 2002). During the 2001 National Fire Roundtable, TNC proposed a new initiative to address the challenges surrounding fire-dependent ecosystem restoration that was modeled on their existing Conservation Learning Networks. The FLN was organized that year and formalized with a cooperative agreement, Restoring Fire Adapted Ecosystems, that was signed in 2002 between TNC, the Forest Service, and the land management agencies of the Department of the Interior (Goldstein et al. 2010). The primary purpose of the FLN was and is to foster collaborative planning, implementation, and adaptive management, as well as to share lessons learned across agencies and landowners operating at different scales and levels (TNC 2012).

To increase prescribed fire implementation and build local and regional capacity, the FLN provides training for firefighters through the TREX initiative (TNC, unpublished manuscript). Two of the specific training objectives are to host workshops that engage federal, state, and private entities in an "interagency learning environment" and to "build skills of non-fire federal employees" (TNC, unpublished manuscript, p. 5). The exchanges began in 2008 with several prescribed fires in Nebraska and Texas and a total of 75 participants that year. There has been significant growth in the number, size, and geographic dispersal of these training events, which in 2013 took place in 4 states, provided training to 220 participants, and established a relationship with Student Association for Fire Ecology chapters at universities across the United States (Bailey et al. 2012). Although the TREX engages federal and nonfederal participants, it is unique among fire training opportunities in the extent to which it serves nonfederal personnel. For instance, the National Interagency Prescribed Fire Training Center (2012) also provides training in prescribed fire application. However, from 2011 to 2013 this Prescribed Fire Training Center's trainee population was $87 \%$ federal employees; during the same time period, only $21 \%$ of the TREX participants were from federal agencies (Table 1).

In previous research, Butler and Goldstein (2010) found that the FLN had the potential to contribute to increased adaptive capacity of fire management institutions in the United States. They explain that by allowing for information exchange and improving learning and innovation, "multiscalar collaborative networks such as the FLN can facilitate overcoming the rigidity traps that prevent resource management agencies from responding to complex cross-scalar problems" (Butler and Goldstein 2010:21). We suggest that in this way the FLN may be acting as a bridging organization that affects fire management institutions in the United States. According to Crona and Parker (2012), bridging organizations are organizations that exist in their own right and link actors or groups through a strategic bridging process. Although knowledge sharing is often a key activity of bridging organizations, by creating networks they can also serve other functions, such as building trust, fostering learning and innovation, connecting government and nongovernment actors, and leveraging needed resources. In this way, scholars suggest that such organizations can contribute to adaptive capacity and adaptive governance (Berkes 2009, Crona and Parker 2012). 
Adaptive governance is a type of environmental governance that can support learning and change through adaptive management and is characterized by interactions between institutions, networks, and actors that can adjust in response to changing conditions at various scales; importantly, adaptive governance is catalyzed by institutions with adaptive capacity (Chaffin et al. 2014). Therefore, the key question is how the TREX, as part of the FLN's activities, contributes to the FLN's role as a bridging organization and whether these activities also promote increased adaptive capacity in an area of social-ecological systems governance that has been characterized by rigidity.

Table 1. A comparison of participant agency affiliation between the Prescribed Fire Training Exchange (TREX) and the Prescribed Fire Training Center (PFTC) training models, 2011-2013. ${ }^{\dagger}$

\begin{tabular}{|c|c|c|}
\hline \multirow[t]{2}{*}{ Participant Host Organization } & \multicolumn{2}{|c|}{ Training Model } \\
\hline & $\operatorname{TREX}(\%)^{\ddagger}$ & PFTC $(\%)^{\ddagger}$ \\
\hline \multicolumn{3}{|l|}{ Federal government } \\
\hline Forest Service & 8 & 58 \\
\hline Bureau of Land & 3 & 6 \\
\hline \multicolumn{3}{|l|}{ Management } \\
\hline National Park Service & 3 & 11 \\
\hline Fish and Wildlife Service & 3 & 9 \\
\hline Bureau of Indian Affairs & 0 & 1 \\
\hline $\begin{array}{l}\text { Other federal agencies/ } \\
\text { military }\end{array}$ & 4 & 2 \\
\hline Total & $\begin{array}{c}21 \\
(\mathrm{n}=99)\end{array}$ & $\begin{array}{c}87 \\
(\mathrm{n}=342)\end{array}$ \\
\hline \multicolumn{3}{|l|}{ Nonfederal government } \\
\hline $\begin{array}{l}\text { State, tribe, or local } \\
\text { government }\end{array}$ & 19 & 7 \\
\hline $\begin{array}{l}\text { Nongovernmental } \\
\text { organizations }\end{array}$ & 21 & 1 \\
\hline Private enterprise & 9 & 1 \\
\hline International participants & 10 & 4 \\
\hline University students & 20 & $0^{\S}$ \\
\hline Total & $\begin{array}{c}79 \\
(\mathrm{n}=372)\end{array}$ & $\begin{array}{c}13 \\
(\mathrm{n}=44)\end{array}$ \\
\hline Total n & 471 & 386 \\
\hline \multicolumn{3}{|c|}{$\begin{array}{l}{ }^{\dagger} \text { These years were chosen because the PFTC provided participant } \\
\text { data for 2011-2013, and the TREX data for these years was the most } \\
\text { reliable (National Interagency Prescribed Fire Training Center 2012). } \\
{ }^{\ddagger} \text { These numbers include participants and field coordinators/ } \\
\text { facilitators at all TREX events, as well as PFTC 20-day sessions and } \\
\text { workshops from } 2011 \text { to } 2013 \text {. } \\
\S \text { The PFTC enrollment information included affiliations for all } \\
\text { participants. No university affiliations were indicated; it may be } \\
\text { possible that participants could also be enrolled as university students. }\end{array}$} \\
\hline
\end{tabular}

\section{Objectives}

Given the importance of prescribed fire for ecosystem management, the need for training opportunities and increased capacity for prescribed fire across jurisdictions, and the TREX's objectives to build cross-jurisdictional capacity, we investigated several aspects of the TREX initiative, which has not yet been examined by third-party researchers. Our research questions were as follows: (1) What are the professional and institutional barriers fire professionals observe in their careers in fire management, how does the TREX address these barriers, and does it contribute to increasing workforce capacity in this area? (2) Is the TREX, as part of the FLN, serving as a bridging organization and contributing to the adaptive capacity of fire management institutions in the United States?

\section{METHODS}

The model for collaborative evaluation, which directs researchers and research subjects to work together in planning an organizational evaluation, guided the design of our study on the TREX training method (Rodríguez-Campos 2012). According to this model, by involving the stakeholders directly in the initial research design and during the research itself, there is an increased likelihood that the results will be useful to those being evaluated (O'Sullivan 2012). We approached staff from the FLN with the study concept early on in the process of designing this project, and the research objectives were developed jointly. Although the TREX model has never been investigated, the FLN has previously undergone several years of study by third-party researchers, which indicates an organizational culture that welcomes evaluation (Taut 2008, Butler and Goldstein 2010).

We conducted the research using multiple case studies of individual TREX events to determine how these events function and why they are needed. As described by Yin (2009), there are strengths to a case-study approach, such as the ability to research events in context and depth, as well as weaknesses, such as limited generalizability and the possibility of selection bias. Our goal was to conduct an in-depth examination afforded by case studies and to conduct as many case studies as was reasonable within a twoyear research time frame to increase our generalizability and understanding of the TREX events. Within our case studies, we utilized a mixed-methods approach, using both qualitative and quantitative procedures. Mixed-methods approaches build on the strengths and minimize the weaknesses of qualitative and quantitative work, allowing the researcher to build a grounded and pragmatic understanding of the research topic (Creswell 2009). Our particular mixed-methods approach, which is described subsequently, is referred to as a concurrent triangulation strategy (Creswell 2009). We chose this approach to collect quantitative and qualitative information simultaneously, which we then analyzed separately and compared for both common themes and disparities. We applied this method to acquire a wealth of data from the point of view of developers, participants, and observers, providing a full picture of the training model.

\section{Site locations}

TREX events have occurred across the Great Plains and western United States since 2008. Some of these exchanges occur annually, and some are one-time events. A total of 5 TREX events took place in 2013. We chose 4 of these for site visits to capture both the variation in events and to allow for a programmatic synthesis of results across these 4 cases (Yin 2009; see Box 1). The fifth event took place in the Loess Hills of Iowa shortly after the Niobrara Valley TREX. We could not attend this event for logistical reasons. A total of 35 firefighters attended the Loess Hills TREX in 2013, and, like the Niobrara Valley event, it occurred on lands managed by TNC and had taken place several years in a row. To include this event, TNC distributed our surveys to participants, and we then used those surveys in the quantitative analysis. 


\section{Box 1:}

Case-study locations of Prescribed Fire Training Exchange (TREX) events in 2013

\section{The Niobrara Valley, Nebraska}

The 56,000-acre (22,662 ha) preserve is owned and managed by the Nature Conservancy (TNC) and caters particularly to university students. This TREX was an ideal site to observe how a large event with a long-standing precedence operates.

\section{Black Lake, New Mexico}

The Forest Guild, an organization that promotes responsible forestry, hosted its first TREX with TNC serving as support. The goal was to build local capacity for more prescribed burns in the future by applying prescribed fire to New Mexico state lands.

\section{Arcata, California}

The Northern California Prescribed Fire Council, which promotes the use of prescribed fire, collaboratively planned this TREX with TNC in northern California. It involved prescribed burn operations on both public and private lands to build local capacity.

\section{Santa Fe, New Mexico}

The international TREX was conducted in Spanish and English. Run by the Fire Learning Network with Forest Service support staff and using the same basic model as the other TREX events, participants were fire management professionals from across Latin America and Europe. It served as an example of how the basic training model could be adapted to serve a group of participants with needs that differ from those of most U.S. firefighters.

\section{Qualitative methods: interviews, focus groups, and participant observation}

Qualitative methods included interviews, focus groups, and participant observation. Our goal in conducting interviews was to explore the training model design. To this end, we conducted interviews with a total of 13 individuals, including the 2 primary training designers from TNC. Using a purposive sampling procedure, we also interviewed willing TREX facilitators at each of the study sites; these individuals were from TNC, other nongovernmental organizations, the National Park Service, the Forest Service, private contracting organizations, and municipal fire departments. The interviews were semistructured and based on an interview guide that was flexible, allowing conversations to focus on each subject's knowledge base and experience with the fire community and the FLN (Kvale 1983, Charmaz 1991, Leech 2002). Questions focused on 3 major topics: the participants' background and experience within the fire community, where they face barriers to or find opportunities for professional development, and their perspectives on fire's role in the environment and hindrances to its use.

In addition to interviews, we conducted semistructured focus groups at each of the TREX study sites, with the exception of the Spanish-language event, where we distributed and later translated responses to a questionnaire reflecting focus group questions.
Participation was voluntary, and we welcomed all willing participants; on average, 10 to 15 individuals participated in each focus group. The purpose of the focus groups was to understand participant experience levels, occupation and educational backgrounds, motivations for attending a TREX, perspectives on prescribed fire and professional development, and satisfaction with the various aspects of the TREX events. The focus group format allowed us to garner perspectives from more individuals than we could have interviewed one-on-one given the format and timing of the TREX events. Focus groups were also a valuable approach in this context because they allowed participants to interact freely in a way that encouraged the sharing of ideas (Kitzinger 1995).

We audio recorded, transcribed, and coded all the interviews and focus groups for themes using a modified grounded theory approach (Peabody et al. 1990, Aberbach and Rockman 2002, Corbin and Strauss 2008). This process involved identifying themes and developing codes that we used to label recurrent themes within the transcriptions. Original codes were based on our research questions and objectives; additional codes emerged from the data as we conducted our analysis. We then used recurrent themes to inductively build conclusions that were "grounded" in the data.

Additionally, the lead author was incorporated into the training events as a participant, i.e., a firefighter during the operations. This allowed for further understanding of the nature of the training events through the recording of detailed field notes and the incorporation of the opinions of those who were not formally interviewed individually or in focus groups (DeWalt and DeWalt 2010, Emerson et al. 2011). Prior to this research, the authors were not affiliated with the FLN or TNC, and we used quantitative survey methods in an effort to reduce the potential for bias through qualitative research methods.

\section{Survey design and analysis}

Quantitative data collection, in the form of measurable satisfaction surveys, was integral to understanding the demographic trends, motivation for attendance, satisfaction levels, and professional backgrounds of participants. We administered surveys at all the case-study sites as part of the operational "after-action review," when participants and trainers reflected on and evaluated the efficacy of the training. We also emailed the survey to past participants using addresses provided by the FLN and sent follow-up prompts to encourage respondents to return the surveys. E-mail addresses were not available for every past participant, and we only included participants with functioning e-mail addresses when calculating our response rate. The survey questions were drafted, edited, and finalized using commonly accepted survey guidelines from Vaske (2008), and they were offered in both English and Spanish. These quantitative methods served to build findings that were generalizable beyond the four case studies.

The paper-based survey distributed at the case-study sites in 2013 received a $100 \%$ response rate of individuals present during the review process, for a total of 116 on-site survey responses. The general population survey, or surveys e-mailed to past participants, received a response rate of $58.5 \%$ with 96 completed surveys. We identified individuals who had attended multiple training events and completed multiple surveys, and we removed 
duplicates from analysis so that only their most recent survey was included in the final analysis. After removing duplicate surveys from people who had attended more than 1 of the case-study training exchanges, there were a total of 204 individual respondents. The FLN estimates that between 2008 and 2013 there have been approximately 590 individuals who have participated in a TREX event; therefore, the 204 survey respondents represent about one-third of the total number of individuals that have participated in a TREX event during that time period. We compared satisfaction rates in multiple categories from paper-based survey results to the e-mail surveys, performing analysis of variance tests between the 4 on-site and e-mail survey populations independently, as well as $t$ tests between the paperbased and the e-mail survey populations. We found no significant differences between these populations during this analysis.

\section{RESULTS}

\section{The design of Prescribed Fire Training Exchange events to increase workforce capacity}

According to TREX designers, engaging nonfederal and local professionals was a central purpose of creating the TREX, in light of the shortage of necessary personnel in fire management generally and the need to build local capacity both inside and outside of the federal government. In our interviews, one TREX facilitator noted, "If we're going to build local capacity, [we have to ask] is there local capacity to burn on non-federal lands in New Mexico? ... [Through the TREX], we opened the doors for a lot of local people to increase their experience." Another facilitator, from the Northern California Prescribed Burn Council, found that "[small] NGOs and private landowners really have no access to prescribed burning, either for training or for use on their property. ... This kind of program gives those people an opportunity to get hands-on experience, work with federal partners, learn from agencies who have a lot of experience, and build relationships." Serving nonfederal personnel was a niche that the TREX model was designed to fill, and it appears to be serving this purpose (Table 1).

We found that the TREX model incorporates all three key aspects of career preparation for fire professionals, as recommended by Kobziar et al. (2009), albeit to different extents. The first day of a TREX event is reserved for educational sessions that describe the local conditions, including the socioeconomic history of the region and ecological objectives of the prescribed burn to be performed, so that the participants understand the local needs and challenges. These sessions are taught by a combination of university educators and local natural resource managers; they usually include field trips to areas that have been through a restoration treatment or affected by a wildfire. This feature of the TREX provides an important but relatively small piece of the "education" aspect of the professional development triangle, which generally refers to a formal degree gained through university-level education. The "training" aspect of the professional development triangle refers to NWCG courses. These training courses are a standardized way to introduce firefighters to the terminology and concepts that they will need in wildland fire operations, and the NWCG "taskbook" process is primarily a field-based checklist of skills that all professional wildland firefighters must complete to achieve higher certification levels. The TREX model does not circumvent these NWCG requirements. At TREX events, new firefighters are offered access to the basic NWCG firefighter courses along with basic training in the field, whereas more experienced participants are encouraged to complete advanced tasks in their NWCG taskbooks. Finally, participants from different agencies, companies, and schools are put into mixed "squads" during TREX events to develop their professional networks and learn different techniques and information. Participants conduct the prescribed burn including ignition, holding the fire within the intended boundaries, extinguishing, and patrolling the perimeter over the course of the training. This is the "experience" aspect of the triangle. Although this is the basic format for the TREX events, the structure is intended to be flexible to the needs of participants and the local conditions.

Demographic composition of these events is diverse (Table 2). TREX events bring in veteran support staff for safety and to train others, early career to midcareer professionals who are looking to network and develop their NWCG certifications, and inexperienced individuals, often students, who are looking for their first experience in fire operations. Although many individuals had experienced working directly with fire, $21 \%$ had never been involved in prescribed fire or wildfire suppression at all.

Table 2. Prescribed Fire Training Exchange participant demographics.

\begin{tabular}{lcccc}
\hline \hline & \multicolumn{2}{c}{ Sex } & & \\
\cline { 2 - 3 } Age Group $^{\dagger}$ & Male (\%) & Female (\%) & Total (\%) & Total (n) \\
\hline $18-26$ & 74 & 26 & 23 & 46 \\
$27-39$ & 86 & 14 & 46 & 94 \\
$40-60$ & 88 & 13 & 28 & 56 \\
$60+$ & 88 & 13 & 4 & 8 \\
Total & 84 & 16 & 100 & 204 \\
\hline
\end{tabular}

${ }^{\dagger}$ Ages were grouped to represent the early career firefighters and traditional student age group (18-26), midcareer professionals (27-39), later career professionals (40-60), and veterans/retired (60+).

\section{Participant motivation for attending and satisfaction with Prescribed Fire Training Exchange events}

The results for participant satisfaction levels were overwhelmingly positive, with an overall composite score of 7.69 out of 9 , corresponding to "very satisfied"; $99.5 \%$ of respondents said they would recommend attending an exchange to a friend (Table 3). Based on the survey, the motivation for attending a training exchange correlates to the experience level of the participant, and as experience level increases, so does the variation in motivation (Table 4). Individuals with low experience overwhelmingly want hands-on experience in fire operations. This motivation decreases as experience level increases but is present for individuals at all experience levels. Data from focus groups indicate that the nature of this motivation also changes as experience increases: veteran firefighters want experience in new fuel types and different terrain, whereas new firefighters want to experience putting fire on the ground for the first time. As wildland fire experience increases, so does the desire for NWCG certifications and taskbook-associated experience. Highly experienced individuals have the most variation in primary motivation for attending a TREX event and the most written-in responses (Table 4). Commonly written-in 
responses regarding motivations in this group were networking and a desire to share professional experience and expertise with new firefighters.

Table 3. Prescribed Fire Training Exchange participant satisfaction ratings. ${ }^{\dagger}$

\begin{tabular}{lccc}
\hline \hline Training Feature & Mean & $\begin{array}{c}\text { Standard } \\
\text { Deviation }\end{array}$ & $\begin{array}{c}\text { Standard } \\
\text { Error }\end{array}$ \\
\hline Location & 7.69 & 1.465 & 0.103 \\
Curriculum & 7.36 & 1.457 & 0.102 \\
Trainers & 7.86 & 1.373 & 0.096 \\
Overall satisfaction & 7.87 & 1.282 & 0.090 \\
Composite score & 7.69 & 1.198 & 0.083 \\
\hline
\end{tabular}

${ }^{\dagger}$ Scores were reported from 1 (unsatisfied) to 9 (extremely satisfied).

Table 4. Reported motivation for attending a Prescribed Fire Training Exchange event, comparing experience levels. ${ }^{\dagger}$

\begin{tabular}{|c|c|c|c|c|}
\hline & \multicolumn{3}{|c|}{$\begin{array}{c}\text { Participant Experience } \\
\text { Level }^{\ddagger}\end{array}$} & \multirow[b]{2}{*}{$\begin{array}{l}\text { Total }(\%) \\
(\mathrm{n}=204)\end{array}$} \\
\hline & $\begin{array}{c}\text { Low } \\
(\%) \\
(\mathrm{n}=65)\end{array}$ & $\begin{array}{c}\text { Medium } \\
(\%) \\
(n=68)\end{array}$ & $\begin{array}{c}\text { High } \\
(\%) \\
(\mathrm{n}=71)\end{array}$ & \\
\hline $\begin{array}{l}\text { Getting hands-on } \\
\text { experience and learning } \\
\text { how to conduct prescribed } \\
\text { burns }\end{array}$ & 79 & 50 & 27 & 51 \\
\hline $\begin{array}{l}\text { Developing my official fire- } \\
\text { related certifications and } \\
\text { job qualifications }\end{array}$ & 8 & 32 & 39 & 27 \\
\hline $\begin{array}{l}\text { Gaining an understanding } \\
\text { of the legal requirements } \\
\text { involved when conducting a } \\
\text { prescribed burn }\end{array}$ & 6 & 10 & 11 & 9 \\
\hline Other ${ }^{\S}$ & 8 & 7 & 21 & 12 \\
\hline
\end{tabular}

\footnotetext{
${ }^{\dagger}$ Experience level was reported from 1 (no experience) to 9 (extremely experienced). The results were recoded as low experience (1-3), medium experience (4-6), and high experience (7-9).

*The results are significant and typically correlated: $\chi^{2}=41.524, \mathrm{P}$ $=<0.001$, and Cramer's $\mathrm{V}=0.319$.

${ }^{\S}$ Respondents were allowed to write in another motivation; the most common write-in was "networking."
}

With the disparate motivations and experience levels represented in training exchanges, there is the potential for variation in satisfaction rates; however, we did not find that this was the case. After testing for homogeneity of variance and conducting analysis of variance tests, we found no statistically significant differences between primary motivation for attending an exchange or experience level and the composite satisfaction rate. In other words, the TREX events appear to offer something of value to all participants, and individuals are satisfied with their experiences at these events, despite varying levels of experience and motivations for attending.
Firefighter perspectives on professional development and the value of Prescribed Fire Training Exchange events

Another key research objective was to investigate firefighter perceptions of barriers they encounter in their careers and the value of TREX events in overcoming those barriers. We discuss these findings subsequently, organized for readability according to the three key components of professional development in fire: training, experience, and education.

\section{The rigidity of traditional training opportunities}

All professional firefighters in the United States must attain NWCG taskbook certifications, referred to as "training" by fire management scholars. In general, the majority of firefighters at TREX events view training courses from the NWCG as valuable, though imperfect. "The NWCG standards are exactly that, they are the standards [that we] have been trained in all across the board ... [but] interaction facilitates people sharing different perspectives, and that's something you do not necessarily get if you are flipping through that [taskbook]," explained a firefighter in New Mexico. Some NWCG courses can be completed online or in regional fire academies, but the taskbook process cannot be completed without specific opportunities in the field. The NWCG is a partnership between primarily federal and state land management organizations, and participants in all the case studies identified agency affiliation as the most important barrier to accessing these training opportunities. Contractors, private landowners, and professionals working with small agencies or municipal fire departments may have experience with fire but often lack the time or funding needed to obtain advanced certifications. Participants said experience level also matters. When attempting to fulfill taskbook requirements during a fire operation, there is often competition between firefighters who need to complete the same tasks. As one person explained, "It's more about where you stand, do you have seniority? Is somebody else competing for that same qualification?" A nongovernmental organization employee described another important barrier this way: "It is not my [primary] job to [suppress] wildfires ... somebody who is on a [fire] engine can do a couple of taskbooks in one summer, while I've been working on [one taskbook] for two years now." Our findings indicate that there are barriers in this area of professional development for both nonfederal workers and federal workers that make up the contingent workforce, i.e., individuals who do not work in fire management as their primary job responsibility.

The TREX strategy addresses some of the barriers to formal NWCG training in two ways. First, it offers training to primarily nonfederal firefighters, who have limited training opportunities compared to federal firefighters. "If you are part of the suppression industrial complex, you've got money backing [you], and opportunity for training, but if you are somehow on the fringes of that, you [have to search for] opportunities to work through the NWCG process that does not necessarily exist to support you in any way. So, I think TREXs are very good in that they address this underserved population," explained a focus group participant. This sentiment was reflected by firefighters from many different backgrounds. Second, TREX participants are invited to discuss their training needs with the trainers prior to the prescribed burn operations, so that their needs can be accommodated. Although the TREX model is able to overcome some barriers in attaining NWCG taskbook requirements, 
participants noted the NWCG certification process is still tailored both to those in the federal system and to the suppression-centric model, in that some tasks can only be completed through wildfire suppression. These tasks cannot be addressed easily in a training scenario, because wildfire operations cannot be simulated to fulfill taskbook requirements (NWCG 2013).

Professional experience and the value of experiential learning Although the NWCG training qualification standards are vital for career development, firefighters need experience with fire on the ground. We found that novice firefighters value experience because it allows them to apply concepts that they learned in school or training courses and become more comfortable in the field through observation. Veteran fire professionals value opportunities to gain new experiences in different fuel types and unfamiliar regions. A veteran firefighter explained, "If you think you know it all, it's time for you to [retire], because now you are a risk ... especially nowadays [because] our climate has changed [and] our fuels have changed." We found, therefore, that the experience component of the fire professional development triangle is valued by all firefighters, even the very experienced; this also indicates that a lifelong learning model is key to proficiency in fire management. The barriers to achieving this onthe-ground experience are similar to those discussed previously, in that contingent firefighters not in the federal government, with less experience, or with jobs that are not primarily focused on fire have fewer opportunities to gain hands-on experience with fire. The TREX offers this experience for all participants.

In addition to providing this on-the-ground experience, we also found that the supportive learning environment of the TREX was highly valued by attendees. At the TREX event in Nebraska, several student participants said that working alongside seasoned veterans and being able to ask questions was a unique and valuable opportunity. One first-time firefighter particularly valued the chance to do this "in a relatively safe and supportive setting, versus just having done the [S-130/190 basic NWCG firefighting course]." This firefighter went on to say, "[After that course], if my first experience with actual fire [would be] going out on a wildfire? I think that would be terrifying. It's nice to have this middle step." Another participant had five years of experience in fire operations but never had an opportunity to lead or supervise under controlled conditions. When in a trainee-supervisory role at a TREX, firefighters perform their duties with an experienced observer to answer questions and provide support in case of an emergency. "In this training it's pretty exciting because personally I get to work outside of where I'm comfortable," the participant explained. Typically, in fire operations there is little discussion of the tactics, strategies, and logic behind the decisions that the upper-level managers make, which means there are fewer opportunities to think critically and learn while gaining experience. Based on our observation and findings, the TREX model encourages this dialogue.

\section{Education as an increasingly important component of professional development}

Among TREX participants, we found no consensus on the value of formal education. University students comprised $20 \%$ of all TREX participants from 2008 to 2013, which allowed us to incorporate student and nonstudent perspectives on the importance of education in the fire community. Respondents viewed fire suppression as a skill set that is dependent solely on experience and training. "I think the degree, depending on what you study, will give you an understanding of [the ecological] processes that are happening on the landscape ... But directly fighting fire? I don't see why [a degree matters]," explained a contractor. However, in cases in which there is an emphasis on ecological integrity as a management objective in prescribed fire, some participants said formal education was more valuable. We observed that this variation in perspectives on education causes discord in the firefighting community represented at TREX events. A federal participant with a graduate degree described working alongside firefighters "whose focus was suppression, and I remember they would make fun of me because I was into prescribed fire [for the] ecological benefits."

Participants explained that there are significant barriers to attaining a formal education because it is often difficult to develop operational experience and training qualifications while pursuing a degree. Similarly, people noted that it can be challenging to attain a degree as a career firefighter. As one person said, "There is the academic track and the operational track, and it is hard to move up without following one of those tracks wholeheartedly. Especially when trying to get into a fire management position without a ton of fire experience, you need some really strong [NWCG qualifications], and that is really hard to achieve if you are simultaneously attending school."We found that students and federal employees were more accepting of educational standards, whereas contractors and municipal firefighters were not, because it can hold them back from entry or advancement in the federal system that dominates fire management.

The TREX serves to bridge some of the gaps between populations with either more education or experience. Some participants indicated that the diversity of attendees at TREX events, which includes both those formally educated in fire science and those who are not, helps to facilitate increased learning, dialogue, and respect across these populations. Furthermore, university students attending TREX events are able to supplement their education with field experience. A TREX designer explained, "University students are already in an academic environment and are already getting lots of great knowledge from excellent instructors ... So we're trying to give them as many days of fire experience as possible."

Also, the educational sessions are an important component of the TREX model, designed to introduce all the participants to the local context and provide a basic understanding of fire ecology for those without an educational background in the subject. However, although the satisfaction scores were very high in all categories, the educational curriculum was rated lower than other training components. The variation in preference and approval for educational sessions would be challenging to address, given the diverse makeup of participants and disparate training desires.

\section{DISCUSSION}

The direct and applied value: Prescribed Fire Training Exchange's role in increasing workforce capacity

Although there are several barriers to increasing the use of prescribed fire, one of the most important is a lack of qualified, available personnel (WFLC and NASF 2009). To conduct prescribed fire at ecologically meaningful scales, i.e., landscapes 
large enough to affect fire behavior and restore key components of ecosystems across multiple jurisdictions, it is necessary to build up a capable national workforce for fire management both inside and outside of the federal government. Federal agencies cannot operate in the same way on private and state lands as they do in their own jurisdictions, and with dwindling federal budgets, agencies need to leverage a wider variety of resources.

One way to accomplish this is to provide training to nonfire natural resource professionals such as private landowners, foresters, ranchers, loggers, students, and researchers. According to our interviews with the trainers and TREX developers, providing training to municipal fire departments can be especially valuable because they have access to specialty vehicles and equipment. TREX is fulfilling this niche to some degree, particularly by providing the necessary training to people in the nonfederal workforce. However, there are persistent barriers to career development for these fire professionals because the NWCG standards are not as accommodating to nonfederal personnel.

Another challenge is the divide, not only between federal and nonfederal workers but also between permanent or permanentseasonal firefighters and those who serve as the contingent workforce, such as contractors or others whose primary work responsibilities are not in fire management. Virtanen et al. (2003) observed that there is an enduring inequality between permanent and contingent workers that results from training opportunities that are offered to the permanent workforce but are not as accessible to the contingent workforce. Our findings indicate that this inequality exists among fire professionals. Contingent workers within the federal workforce said they found TREX events valuable for helping them gain the experience and training they needed to work in fire management. Nonetheless, federal employees who were not full-time firefighters and nonfederal employees both noted they were at a disadvantage for gaining the training they needed to work in prescribed fire. The TREX alone, as a training model at its current scale, is limited in its ability to address entrenched systemic challenges such as these, which will require attention to fully leverage the capacity that can be gained from engaging a broader range of natural resource professionals.

The TREX strategy appears to have value in meeting a variety of professional development needs, whether individuals are seeking official NWCG qualifications, a first experience with prescribed fire, or familiarity in new fuel types. Because it was designed to be a flexible training strategy that allows participants to discuss their training desires and learn from each other, the TREX accommodates the needs of a diverse group of students and professionals. The director of the FLN explained that the training model "is not a program; it is a strategy, which means it has to be nimble, and it is not always the same tool"; in other words, the flexibility of the approach is central to its purpose and design. This flexibility appears to be key to the strategy's utility for a variety of participants, as evidenced by the high levels of satisfaction across participants with varying needs and levels of experience.

A critique of the current paradigm for professional development in fire management is the difficulty in accessing all three aspects of the professional development triangle in a person's career (Kobziar et al. 2009). By incorporating NWCG training with experiential learning and ecological education sessions, the TREX strategy has developed an approach that includes, to some extent, the key features of the fire professional development triangle model. Of particular value is that the TREX events offer operational experience, which we found is desired by all levels of participants, from experienced veterans to inexperienced firefighters. However, although acquiring experience in a learning environment may be valuable to all experience levels, it is especially important for new firefighters with a formal education. As Kobziar et al. (2009) note, it can be particularly difficult for those with adequate education to get the appropriate experience and training they need to be prepared for a career in fire. Although the TREX is not a solution for all professional development needs in fire, it provides important access to experience for students, who comprise an important and growing proportion of TREX attendees. In this way, the TREX addresses some of the challenges highlighted by Kobziar et al. (2009).

Given current management challenges, the opportunity provided to students may be one of the most significant benefits of the TREX. If ecologically oriented outcomes are the management objectives, as they are in the National Fire Plan, and prescribed fire is a tool that can be used to meet these goals, then fire professionals need to be prepared with an adequate educational background (Kostishack and Rana 2002). A TREX designer observed, "When we have entire operating units [such as national forests] who only have one fire ecologist at the regional level, what kind of model is that?... We need a fire ecologist on every district." Formal college education is not an outcome of the TREX training model, but by integrating Student Association for Fire Ecology chapters, a substantial number of students are able to get field experience and develop NWCG certifications. Career development programs need to consider the environmental, political, and economic realities that the next generation of workers will encounter (Campbell 1997). If fire management is to focus less exclusively on suppression, then training strategies need to integrate the educated natural resource professionals while providing education to the already integrated firefighters.

\section{Broader contributions to adaptive capacity of fire management institutions}

The FLN has been highlighted as a kind of governance approach that could serve to increase adaptive capacity in fire management. An important question in our research is whether the TREX, a component of the FLN that has not yet been evaluated, is contributing to the FLN's role as a bridging organization that increases the adaptive capacity within U.S. fire management institutions. Resilience thinking points to the importance of knowledge sharing, acting across scales, promoting learning, and creating social networks to enhance learning and innovation (Folke et al. 2005). Institutional adaptive capacity is increased by including a variety of actors, leveraging valuable resources, increasing opportunities for learning and trust building, and promoting the ability of local actors to act with autonomy and bring their local knowledge to bear on problems (Gupta et al. 2010). We examined our findings to understand how the TREX may be contributing across these characteristics that contribute to adaptive capacity.

Our findings indicate that the TREX is providing opportunities to increase capacity across scales and jurisdictions where existing 
institutions are limited, particularly by increasing the involvement of nonfederal fire professionals. In this way, the TREX is allowing the FLN to serve in the role of a bridging organization by bringing together government and nongovernmental actors and developing a network made up of actors, including individuals and organizations, that traditionally do not interact. Multilevel and cross-scale networks can be critical for handling environmental governance challenges that require attention at specific yet dynamic scales, as is the case with fire. Restoration and fire management must be addressed at a scale large enough to affect fire behavior and protect resources of interest, and these scales are often mismatched with jurisdictional arrangements (Brown et al. 2004, Cummings et al. 2006, Lebel et al. 2006). Networks can increase adaptive capacity by bringing together specific advantages that exist at various scales and levels, i.e., combining local knowledge and resources with the expertise, data sets, and protocols that regional partners may offer (Berkes 2009). By connecting actors across scales, networks can also increase the variety of actors and resources available and improve coordination (Cummings et al. 2006, Gupta et al. 2010).

The opportunity for participants to share their knowledge across age groups, experience levels, location, and professional affiliations is another aspect of the TREX that may contribute to adaptive capacity, which depends on this kind of opportunity for learning and knowledge transfer (Folke et al. 2005, Gupta et al. 2010). Scholars have also found that diverse participation in learning networks promotes problem solving, trust building, and self-organization to address natural resource challenges (Lebel et al. 2006). The TREX events apply these principles by allowing for collaboration in the design of the events, open communication during the events among mixed "squads" with diverse levels of experience, and collective reflection at the end of events. Participants also indicated that they valued the opportunity to educate and learn from other participants across levels of experience and from different organizations at TREX events. Similarly, developing networks was a primary goal of the TREX and an important reason participants attended. The involvement of students is also an important contribution in this area. Students bring new knowledge to the field, which may be increasingly important to incorporate into the fire professional community in an era of ecological restoration. Students also represent the future generation of fire management, and they are gaining critical field experience through the TREX by interacting and building networks with more experienced practitioners. An important question is whether the networks created at TREX events and the learning that occurs there persist over time. Reed et al. (2010) point out that even when a learning opportunity occurs, learning may not become embedded in a social network. Longitudinal work is needed to understand whether and how efforts such as the TREX actually translate into long-term improvements in adaptive capacity by creating networks and social learning that endure.

Flexibility and emphasis on the local context are aspects of the TREX that align with strategies for increasing adaptive capacity. The four cases we evaluated demonstrate how the TREX can be adapted to local contexts or even be adopted and implemented by a community partner, such as the Forest Guild in New Mexico. The events can be designed to meet the needs of a specific population, as was the case in the Spanish-language event, or educate professionals to conduct burns in different ecosystems or with different management objectives. This attribute was intentionally built into the design of the TREX. Our findings indicate that this flexibility contributes to the strategy's success at offering training events that are of value to the various participant groups. By emphasizing the importance of local context in its educational sessions, the TREX incorporates a commitment to flexibility and context specificity into its design, embedding within the TREX strategy the characteristics of adaptive capacity that have the potential to contribute to increased adaptive capacity of fire management institutions in the United States. The resilience literature consistently points to the need for flexible institutions. Walker et al. (2004) write, "Strategies will be context dependent, and will themselves have to change over time because of the inevitable changes inherent in complex, coupled [socialecological systems]." However, a balance between flexibility and rigidity is needed to adapt institutions to altered environmental conditions at an appropriate pace (Gupta et al. 2010). The TREX model exhibits both of these aspects; it has a structure and adheres to NWCG standards, but it is also distributed and collaboratively designed to tailor events to different ecosystems and participant needs.

\section{CONCLUSION}

The TREX is a key aspect of the FLN's work as a bridging organization. As Crona and Parker (2012) explain, bridging organizations like the FLN exist as single entities that link actors, groups, and organizations through strategic processes like the TREX. Governance contributions from bridging organizations that promote learning, local context specificity, and network building can serve to improve broader institutional adaptive capacity. In an era of increasing complexity and uncertainty in social-ecological systems, it is all the more important that institutions have adaptive capacity to respond to change (Walker and Salt 2012). Scholars suggest that this will eventually require that society moves toward more adaptive governance structures, which can be catalyzed by efforts to increase adaptive capacity (Chaffin et al. 2014). For these reasons, strategies like the TREX are important to consider in the context of the resilience literature, in which examples of how to implement the normative recommendations for promoting adaptive capacity and adaptive governance are still limited (Berkes 2009).

Like Butler and Goldstein (2010), we acknowledge that the TREX as part of the FLN is contributing to what are important but only incremental steps in advancing innovation within and across fire management institutions in the United States. Nonetheless, incremental change is significant. Successful transformations for improving adaptive capacity often begin with informal networks, led by key individuals, that improve knowledge transfer and promote innovation by serving as incubators of new ideas and approaches (Folke et al. 2005). By encouraging innovation and experimentation, the TREX and FLN provide valuable contributions to change in the world of fire management, even if fire management institutions remain rigid.

However, future research is needed to understand whether events like the TREX, which promote many of the hallmark recommendations in the adaptive capacity literature, lead to detectable increases in adaptive capacity that persist within governance institutions. As Gupta et al. (2010) explain, institutions may have increased adaptive capacity, but this does 
not necessarily mean that society will capitalize on this capacity. Longitudinal work would be valuable to determine whether such events lead to increased use of available resources, long-term social learning, the development of networks that are utilized over time, and increased communication, understanding, and action across scales, jurisdictions, and groups of actors. Such increases in adaptive capacity would need to be evaluated to understand whether and how they contribute to improved governance and resilience in fire-adapted social-ecological systems. In summary, we suggest that additional work is needed to understand when efforts to promote adaptive capacity result in increased capacity that persists, how this capacity is then utilized within a governance system to respond to social-ecological challenges, and what factors promote the maintenance and application of adaptive capacity.

Responses to this article can be read online at: http://www.ecologyandsociety.org/issues/responses. $\mathrm{php} / 7847$

\begin{abstract}
Acknowledgments:
This work was supported by the U.S. Department of Agriculture's National Institute of Food and Agriculture, McIntire Stennis project 1006419. The authors would like to thank the Fire Learning Network and the Nature Conservancy for welcoming this research and providing us access to their training events, designers, and participants. We also would like to thank Colorado State University's Department of Forest and Rangeland Stewardship and Center for Collaborative Conservation for their support of this research. This publication comes from a thesis submitted to the academic faculty of Colorado State University in partial fulfillment of the requirements for the degree of Master of Science in Forest Sciences.
\end{abstract}

\section{LITERATURE CITED}

Aberbach, J. D., and B. A. Rockman. 2002. Conducting and coding interviews. Political Science \& Politics 35:673-676. http:// dx.doi.org/10.1017/S1049096502001142

Allen, C. D., M. Savage, D. A. Falk, K. F. Suckling, T. W. Swetnam, T. Schulke, P. B. Stacey, P. Morgan, M. Hoffman, and J. T. Klingel. 2002. Ecological restoration of southwestern ponderosa pine ecosystems: a broad perspective. Ecological Applications 12:1418-1433. http://dx.doi.org/10.1890/1051-0761 (2002)012[1418:EROSPP]2.0.CO;2

Armitage, D. 2005. Adaptive capacity and community-based natural resource management. Environmental Management 35 (6):703-715. http://dx.doi.org/10.1007/s00267-004-0076-z

Armitage, D., and R. Plummer. 2010. Adaptive capacity and environmental governance. Springer, Berlin, Germany. http://dx. doi.org/10.1007/978-3-642-12194-4

Bailey, J., R. Guse, S. Hickey, K. Lapham, and L. Rank. 2012. "Neighbors helping neighbors" spreads like wildfire: innovative learning exchanges develop prescribed fire professionals. Fire Learning Network, The Nature Conservancy, Arlington,
Virginia, USA. [online] URL: https://www.conservationgateway. org/Files/Documents/TREX_NeighborsPoster_Dec2012.pdf

Berkes, F. 2009. Evolution of co-management: role of knowledge generation, bridging organizations, and social learning. Journal of Environmental Management 90:1692-1702. http://dx.doi. org/10.1016/j.jenvman.2008.12.001

Berkes, F., J. Colding, and C. Folke, editors. 2003. Navigating social-ecological systems: building resilience for complexity and change. Cambridge University Press, Cambridge, UK. http://dx. doi.org/10.1017/cbo9780511541957

Brown, R. T., J. K. Agee, and J. F. Franklin. 2004. Forest restoration and fire: principles in the context of place. Conservation Biology 18(4):903-912. http://dx.doi.org/10.1111/ j.1523-1739.2004.521 1.x

Busenberg, G. 2004. Wildfire management in the United States: the evolution of a policy failure. Review of Policy Research 21 (2):145-156. http://dx.doi.org/10.1111/j.1541-1338.2004.00066.x

Butler, W. H., and B. E. Goldstein. 2010. The US Fire Learning Network: springing a rigidity trap through multiscalar collaborative networks. Ecology and Society 15(3): 21. [online] URL: http://www.ecologyandsociety.org/vol15/iss3/art21/

Campbell, C. P. 1997. Workforce requirements: the basis for relevant occupational training. Journal of European Industrial Training 21(8):279-297. http://dx.doi.org/10.1108/03090599710184662

Cash, D. W., and S. C. Moser. 2000. Linking global and local scales: designing dynamic assessment and management processes. Global Environmental Change 10:109-120. http://dx.doi. org/10.1016/S0959-3780(00)00017-0

Chaffin, B. C., H. Gosnell, and B. A. Cosens. 2014. A decade of adaptive governance scholarship: synthesis and future directions. Ecology and Society 19(3): 56. http://dx.doi.org/10.5751/ es-06824-190356

Charmaz, K. 1991. Translating graduate qualitative methods into undergraduate teaching: intensive interviewing as a case example. Teaching Sociology 19:384-395. http://dx.doi.org/10.2307/1318205

Corbin, J., and A. Strauss, editors. 2008. Basics of qualitative research: techniques and procedures for developing grounded theory. Third edition. Sage, Thousand Oaks, California, USA.

Creswell, J. W. 2009. Research design: qualitative, quantitative and mixed methods approaches. Third edition. Sage, Thousand Oaks, California, USA.

Crona, B. I., and J. N. Parker. 2012. Learning in support of governance: theories, methods, and a framework to assess how bridging organizations contribute to adaptive resource governance. Ecology and Society 17(1): 32. http://dx.doi. org/10.5751/es-04534-170132

Cumming, G. S., D. H. M. Cumming, and C. L. Redman. 2006. Scale mismatches in social-ecological systems: causes, consequences, and solutions. Ecology and Society 11(1): 14. [online] URL: http://www.ecologyandsociety.org/vol11/iss1/ $\underline{\operatorname{art14l}}$

Dellasala, D. A., J. E. Williams, C. D. Williams, and J. F. Franklin. 2004. Beyond smoke and mirrors: a synthesis of fire policy and 
science. Conservation Biology 18(4):976-986. http://dx.doi. org/10.1111/j.1523-1739.2004.00529.x

DeWalt, K. M., and B. R. DeWalt. 2010. Participant observation: a guide for fieldworkers. Second edition. Rowman Altamira, Lanham, Maryland, USA.

Dombeck, M. P., J. E. Williams, and C. A. Wood. 2004. Wildfire policy and public lands: integrating scientific understanding with social concerns across landscapes. Conservation Biology 18 (4):883-889. http://dx.doi.org/10.1111/j.1523-1739.2004.00491.x

Emerson, R. M., R. I. Fretz, and L. L. Shaw. 2011. Writing ethnographic fieldnotes. Second edition. University of Chicago Press, Chicago, Illinois, USA.

Folke, C., T. Hahn, P. Olsson, and J. Norberg. 2005. Adaptive governance and social-ecological systems. Annual Review of Environment and Resources 30:441-473. http://dx.doi.org/10.1146/ annurev.energy.30.050504.144511

Garmestani, A. S., and M. H. Benson. 2013. A framework for resilience-based governance of social-ecological systems. Ecology and Society 18(1): 9. http://dx.doi.org/10.5751/ES-05180-180109

Goldstein, B. E., W. H. Butler, and R. B. Hull. 2010. The Fire Learning Network: a promising conservation strategy for forestry. Journal of Forestry 108(3):120-125.

Gorte, R. 2013. The rising cost of wildfire protection. Headwaters Economics, Bozeman, Montana, USA. [online] URL: http:// www.dora.state.co.us/Taskforce/Documents/fire-costs-backgroundreport.pdf

Gunderson, L. H., and C. S. Holling. 2002. Panarchy: understanding transformations in human and natural systems. Island, Washington, D.C., USA.

Gupta, J., C. Termeer, J. Klostermann, S. Meijerink, M. van den Brink, P. Jong, S. Nooteboom, and E. Bergsma. 2010. The Adaptive Capacity Wheel: a method to assess the inherent characteristics of institutions to enable the adaptive capacity of society. Environmental Science \& Policy 13:459-471. http://dx.doi. org/10.1016/j.envsci.2010.05.006

Kauffman, J. B. 2004. Death rides the forest: perceptions of fire, land use, and ecological restoration of western forests. Conservation Biology 18(4):878-882. http://dx.doi.org/10.1111/ j.1523-1739.2004.545_1.x

Kitzinger, J. 1995. Qualitative research: introducing focus groups. BMJ 311:299-302. http://dx.doi.org/10.1136/bmj.311.7000.299

Kobziar, L. N., M. E. Rocca, C. A. Dicus, C. Hoffman, N. Sugihara, A. E. Thode, J. M. Varner, and P. Morgan. 2009. Challenges to educating the next generation of wildland fire professionals in the United States. Journal of Forestry 107 (7):339-345.

Kostishack, P., and N. Rana. 2002. An introduction to the National Fire Plan: history, structure, and relevance to communities. Pinchot Institute for Conservation, Washington, D.C., USA. [online] URL: http://www.pinchot.org/uploads/download?fileId=17

Kvale, S. 1983. The qualitative research interview: a phenomenological and a hermeneutical mode of understanding. Journal of Phenomenological Psychology 14:171-196. http://dx. doi.org/10.1163/156916283X00090
Lebel, L., J. M. Anderies, B. Campbell, C. Folke, S. HatfieldDodds, T. P. Hughes, and J. Wilson. 2006. Governance and the capacity to manage resilience in regional social-ecological systems. Ecology and Society 11(1): 19. [online] URL: http://www. ecologyandsocietyorg/vol11/iss 1/art19

Leech, B. L. 2002. Asking questions: techniques for semistructured interviews. Political Science \& Politics 35:665-668. http://dx.doi.org/10.1017/S1049096502001129

Le Goff, H., A. Leduc, Y. Bergeron, and M. Flannigan. 2005. The adaptive capacity of forest management to changing fire regimes in the boreal forest of Quebec. Forestry Chronicle 81(4):582-592. http://dx.doi.org/10.5558/tfc81582-4

National Interagency Prescribed Fire Training Center. 2012. Session participants. National Interagency Prescribed Fire Training Center, Tallahassee, Florida, USA. [online] URL: $\underline{\text { http:// }}$ www.fws.gov/fire/pftc/session participants.shtml

National Wildfire Coordinating Group (NWCG). 2013. NWCG task book for the positions of: strike team leader crew (STCR), strike team leader heavy equipment (STEQ), strike team leader engine (STEN), task force leader (TFLD). PMS 311-10. NWCG, Boise, Idaho, USA. [online] URL: http://www.nwcg.gov/sites/ default/files/products/training-products/pms-311-10.pdf

The Nature Conservancy (TNC). 2012. Fire Learning Network field guide. TNC, Arlington, Virginia, USA. [online] URL: $\underline{\text { http:// }}$ www.conservationgateway.org/Documents/FLN_FieldGuide_vMarch2012 rev29Apr12 web.pdf

O'Sullivan, R. G. 2012. Collaborative evaluation within a framework of stakeholder-oriented evaluation approaches. Evaluation and Program Planning 35:518-522. http://dx.doi. org/10.1016/j.evalprogplan.2011.12.005

Pahl-Wostl, C. 2009. A conceptual framework for analysing adaptive capacity and multi-level learning processes in resource governance regimes. Global Environmental Change 19:354-365. http://dx.doi.org/10.1016/j.gloenvcha.2009.06.001

Peabody, R. L., S. Webb Hammond, J. Torcom, L. P. Brown, C. Thompson, and R. Kolodny. 1990. Interviewing political elites. Political Science \& Politics 23(3):451-455. http://dx.doi. org/10.2307/419807

Pollet, J., and P. N. Omi. 2002. Effect of thinning and prescribed burning on crown fire severity in ponderosa pine forests. International Journal of Wildland Fire 11:1-10. http://dx.doi. org/10.1071/WF01045

Pyne, S. J. 1982. Fire in America: a cultural history of wildland and rural fire. Princeton University Press, Princeton, New Jersey, USA.

Pyne, S. J. 2010. America's fires: a historical context for policy and practice. Forest History Society, Durham, North Carolina, USA.

Quinn-Davidson, L. N., and J. M. Varner. 2012. Impediments to prescribed fire across agency, landscape and manager: an example from northern California. International Journal of Wildland Fire 21:210-218. http://dx.doi.org/10.1071/WF11017

Rasband, J., J. Salzman, and M. Squillace. 2009. Natural resources law and policy. Second edition. Foundation, New York, New York, USA. 
Reed, M. S., A. C. Evely, G. Cundill, I. Fazey, J. Glass, A. Laing, J. Newig, B. Parrish, C. Prell, C. Raymon, and L. C. Stringer. 2010. What is social learning? Ecology and Society 15(4): r1. [online] URL: http://www.ecologyandsociety.org/vol15/iss4/ $\underline{\text { resp } 1 /}$

Reinhardt, E. D., R. E. Keane, D. E. Calkin, and J. D. Cohen. 2008. Objectives and considerations for wildland fuel treatment in forested ecosystems of the interior western United States. Forest Ecology and Management 256:1997-2006. http://dx.doi. org/10.1016/i.foreco.2008.09.016

Rodríguez-Campos, L. 2012. Advances in collaborative evaluation. Evaluation and Program Planning 35:523-528. http:// dx.doi.org/10.1016/j.evalprogplan.2011.12.006

Ryan, K. C., E. E. Knapp, and J. M. Varner. 2013. Prescribed fire in North American forests and woodlands: history, current practice, and challenges. Frontiers in Ecology and the Environment 11:e15-e24. http://dx.doi.org/10.1890/120329

Schultz, C. A., T. Jedd, and R. D. Beam. 2012. The Collaborative Forest Landscape Restoration Program: a history and overview of the first projects. Journal of Forestry 110(7):381-391. http://dx. doi.org/10.5849/jof.11-082

Stephens, S. L., and L. W. Ruth. 2005. Federal forest-fire policy in the United States. Ecological Applications 15(2):532-542. http:// dx.doi.org/10.1890/04-0545

Taut, S. 2008. What have we learned about stakeholder involvement in program evaluation? Studies in Educational Evaluation 34:224-230. http://dx.doi.org/10.1016/j.stueduc.2008.10.007

Theobald, D. M., and W. H. Romme. 2007. Expansion of the US wildland-urban interface. Landscape and Urban Planning 83:340-354. http://dx.doi.org/10.1016/j.landurbplan.2007.06.002

U.S. Department of Agriculture (USDA) and U.S. Department of the Interior (USDI). 2000. Managing the impact of wildfires on communities and the environment: a report to the president in response to the wildfires of 2000. USDI, Washington, D.C., USA. [online] URL: http://interior.gov/pmb/owf/upload/2000-Reportto-the-President.pdf

Vaske, J. J. 2008. Survey research and analysis: applications in parks, recreation and human dimensions. Venture, State College, Pennsylvania, USA.

Virtanen, M., M. Kivimäki, P. Virtanen, M. Elovainio, and J. Vahtera. 2003. Disparity in occupational training and career planning between contingent and permanent employees. European Journal of Work and Organizational Psychology 12 (1):19-36. http://dx.doi.org/10.1080/13594320344000002

Walker, B., C. S. Holling, S. R. Carpenter, and A. Kinzig. 2004. Resilience, adaptability, and transformability in social-ecological systems. Ecology and Society 9(2): 5. [online] URL: http://www. ecologyandsociety.org/vo19/iss2/art5/

Walker, B., and D. Salt. 2012. Resilience practice: building capacity to absorb disturbance and maintain function. Island, Washington, D.C., USA. http://dx.doi.org/10.5822/978-1-61091-231-0
Westerling, A. L., M. G. Turner, E. A. H. Smithwick, W. H. Romme, and M. G. Ryan. 2011. Continued warming could transform Greater Yellowstone fire regimes by mid-21st century. Proceedings of the National Academy of Sciences of the United States of America 108:13165-13170. http://dx.doi.org/10.1073/ pnas. 1110199108

Western Forestry Leadership Council (WFLC) and National Association of State Foresters (NASF). 2009. Quadrennial fire review 2009: final report. WFLC, Fire Executive Council, and NASF, Washington, D.C., USA.

Yin, R. K. 2009. Case study research design and methods. Fourth edition. Sage, Thousand Oaks, California, USA. 